\title{
PENGGUNAAN SISTEM INFORMASI GEOGRAFIS UNTUK MENGHITUNG DIMENSI LUMPUR PANAS DI PORONG, SIDOARJO
}

\author{
Gatot H. Pramono*) \& Seno P. Sardjono**) \\ *) Peneliti SIG di Bakosurtanal, Jl. Jakarta-Bogor Km 46, Cibinong 16911; \\ **) Staf pengajar di Geofisika ITS, Keputih Sukolilo, Surabaya; \\ E-mail: gatot@bakosurtanal.go.id, senopudji@hotmail.com
}

\begin{abstract}
$\mathscr{Y}$ hot mud extrusion in Porong, Sidoarjo since May 29, 2006 has impacted many aspects including social, culture, economy and transportation. Several weeks later, a collaborative team was formed to investigate the factors controlling the hot mud extrusions. One important aspect is concerning the mud dimensions such as its perimeter, area, volume and discharge. Bakosurtanal was assigned to carry out this task. Field surveys to acquire the mud heights were conducted twice within one month interval. Geographic Information System (GIS) using 3 dimentional approach was employed to compute the mud dimesions. One of the results show that the mud discharge is about $50.000 \mathrm{~m}^{3} /$ day. This value was later commonly used to refer the magnitude of the hot mud.
\end{abstract}

Keywords: GIS, hot mud flow, discharge, natural disaster

\section{PENDAHULUAN}

Semburan lumpur dan gas yang muncul ke permukaan sejak tanggal 29 Mei 2006 di Kecamatan Porong, Kabupaten Sidoarjo, Jawa Timur merupakan suatu bencana alam yang belum selesai sampai tulisan ini dibuat. Sumber dari luapan lumpur adalah dari akuifer bertekanan tinggi pada kedalaman 2.5 - $2.8 \mathrm{~km}$ (Davies, 2007). Hasil dari penelitian Mazzini dkk (2007) menunjukkan bahwa kemungkinan besar telah terjadi goncangan besar di lapisan bawah permukaan sebelum terjadinya luapan lumpur. Gempa di provinsi Yogyakarta dan Jawa Tengah yang terjadi pada 27 Mei 2006 dengan kekuatan 6,2 skala Richter diperkirakan sebagai penyebab terjadinya luapan lumpur.
Dampak dari bencana ini sangat besar terhadap masyarakat dan lingkungan di Jawa Timur. Ribuan orang telah kehilangan pekerjaan dan tidak kurang 24.000 orang mengungsi dikarenakan bencana ini (Cyranoski, 2007). Korban jiwa terbesar sebanyak 10 orang meninggal terjadi ketika pipa gas bawah tanah meledak pada tanggal 22 November 2006 (World Health Organization, 2006). Menurut Joint UNEP/OCHA Environment Unit (2006), dampak lingkungan dari luapan lumpur ini adalah pada lahan pertanian dan wilayah pantai.

Kurang dari sebulan setelah semburan lumpur panas, tim gabungan penanggulangan lumpur dibentuk yang diantaranya beranggotakan staf dari Institut Teknologi 
Sepuluh November (ITS) dan Institut Teknologi Bandung (ITB), Lapindo Brantas Inc dan Bakosurtanal. Tujuan dari dibentuknya tim ini adalah menentukan penyebab semburan lumpur panas. Salah satu yang menjadi pertanyaan yang harus dijawab oleh tim ini adalah berapa dimensi atau besaran lumpur yang sudah meluber. Tujuan dari penelitian ini adalah untuk menentukan dimensi luapan lumpur panas yang terdiri dari keliling, luas, volume dan debit lumpur. Beberapa manfaat akan didapatkan dengan penghitungan dimensi lumpur ini. Volume lumpur yang sudah dikeluarkan ke permukaan akan digunakan untuk memperkirakan lumpur yang akan dimasukkan untuk menghentikan semburan, sedang debit lumpur yang keluar dapat digunakan untuk memprediksi volume lumpur yang akan terjadi pada jangka waktu tertentu.

\section{METODE PENELITIAN}

Untuk menghitung dimensi lumpur panas, Sistem Informasi Geografis (SIG) digunakan. Keliling dan luas lumpur panas diperoleh secara langsung dalam SIG. Ada dua hal yang menjadi tantangan dalam melaksanakan kegiatan ini yaitu menghitung volume lumpur panas dan debit lumpur yang merupakan turunan dari volume lumpur.

Secara sederhana, volume lumpur panas didapatkan dari luas cakupan lumpur dikalikan dengan tinggi genangan lumpur. Karena genangan lumpur berbeda dari satu lokasi ke lokasi yang lain, maka perlu didapatkan ketinggian lumpur pada beberapa titik genangan. Teknologi SIG digunakan untuk menghitung volume lumpur. Penghitungan dimensi lumpur panas dilakukan dalam dua tahap yaitu survei lapangan dan analisa SIG. Tahapan tersebut selanjutnya akan dijelaskan sebagai berikut.

\section{Survei lapangan}

Tujuan dari pelaksanaan survei lapangan adalah untuk mendapatkan batas dari genangan lumpur untuk perhitungan keliling dan luas lumpur. Selain itu, ketinggian lumpur juga dicatat untuk perhitungan volume lumpur. Survei lapangan dilakukan sebanyak dua kali yaitu pada tanggal 21 Juni dan 21 Juli 2006, yaitu 22 dan 52 hari setelah luapan lumpur terjadi pertama kali pada tanggal 29 Mei 2006. Pelaksanaan survei pertama dan kedua yang memiliki selang waktu 1 bulan adalah untuk melakukan analisa multitemporal sehingga perkembangan luasan dan debit lumpur panas dapat dianalisa.

Pengukuran ketinggian genangan lumpur dilakukan di sekeliling genangan lumpur (Gambar 1). Hal ini dilakukan dengan mengukur perbedaaan tinggi antara permukaan lumpur dengan wilayah di sekitar tanggul yang tidak tenggelam. Dalam pengukuran ini diasumsikan dasar permukaan tanah diwilayah tersebut adalah datar. Hal ini sesuai dengan garis kontur yang ada di peta rupabumi Indonesia dan wilayah persawahan yang relatif datar. Pengukuran ketinggian lumpur tidak dapat dilaksanakan di bagian tengah dari wilayah yang tergenang karena tidak mungkin untuk melakukannya dengan kondisi lumpur yang panas dan padat. Estimasi puncak ketinggian dapat dilakukan pada lokasi 200 meter dari sumber luapan lumpur. Hal ini dikarenakan pada saat survei lapangan terdapat aktifitas pembuatan relief well di sekitar pusat semburan. Setelah menanyakan ketinggian timbunan tanah di lokasi tersebut, ketinggian di pusat semburan dapat diperkirakan yaitu tujuh meter.

Peralatan yang digunakan untuk survei lapangan adalah meteran gulung, 

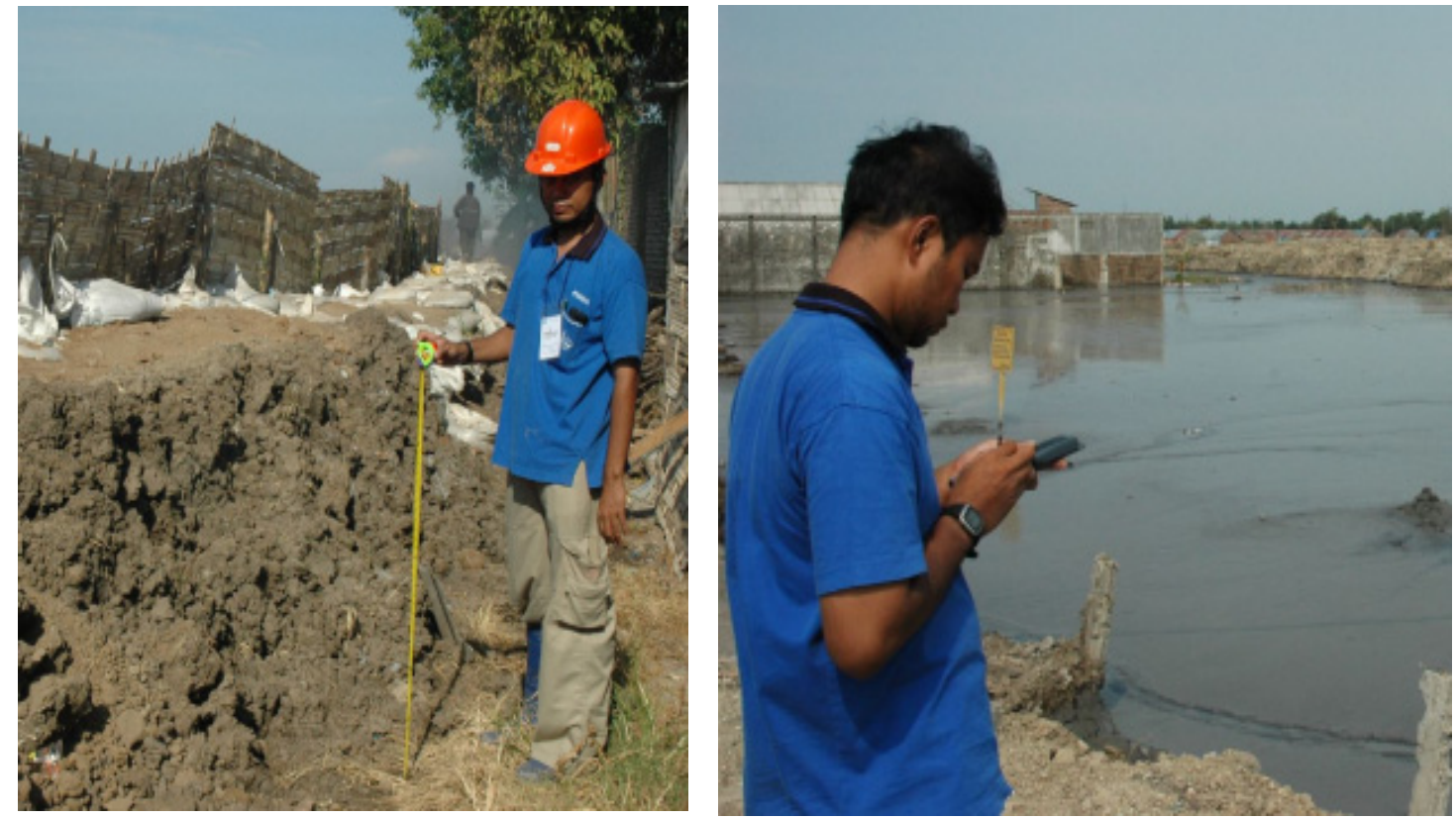

Gambar 1: Mengukur ketinggian lumpur dan menyimpan posisi geografis

Global Positioning Systems (GPS), Personal Digital Assistance (PDA) dan digital camera. GPS yang digunakan adalah GPS 10 Garmin sedang PDA yang digunakan adalah HP Ipaq 12cx. Fungsi dari PDA adalah untuk menyimpan koordinat lokasi pengukuran dari GPS ke dalam file dengan format shapefile. Koneksi tanpa kabel bluetooth digunakan untuk menghubungkan antara GPS dan PDA. Selain itu, ketinggian genangan lumpur dan kondisi lokasi juga dicatat dalam basis data dari shapefile. Pengambilan data dengan metode ini sangat cepat sehingga data bisa diproses langsung dengan perangkat lunak SIG.

Survei lapangan dilakukan selama satu hari penuh dan melibatkan tiga orang. Lima belas titik ketinggian lumpur didapatkan pada survei tanggal 21 Juni 2006, sedang pada survei 21 Juli 2006, 51 titik ketinggian diperoleh. Lokasi titik ketinggian lumpur dapat dilihat pada Gambar 2. Pada survei yang pertama digunakan sepeda mo- tor untuk mempermudah akses ke lokasi, sedang pada survei kedua digunakan mobil karena tanggul penahan lumpur sudah cukup lebar untuk dapat dilewati kendaraan roda empat.

\section{Analisa SIG}

Sistem Informasi Geografis telah banyak digunakan untuk menghitung volume secara spasial. Penrod dkk (2006) telah menggunakan analisa 3 dimensi untuk mengestimasi banjir yang pernah terjadi pada tahun 1889. Tinggi permukaan banjir didapatkan dari bekas titik tertinggi banjir. Digital Elevation Model (DEM) dengan kontur interval $30 \mathrm{~cm}$ juga digunakan. Selain itu, SIG dengan kemampuan analisa 3 dimensi digunakan untuk menghitung volume danau (University of Alberta, 2001). Survei lapangan dilakukan untuk mendapatkan titik kedalaman danau pada beberapa lokasi. Data hasil survei kemudian diubah dalam format Triangulated 

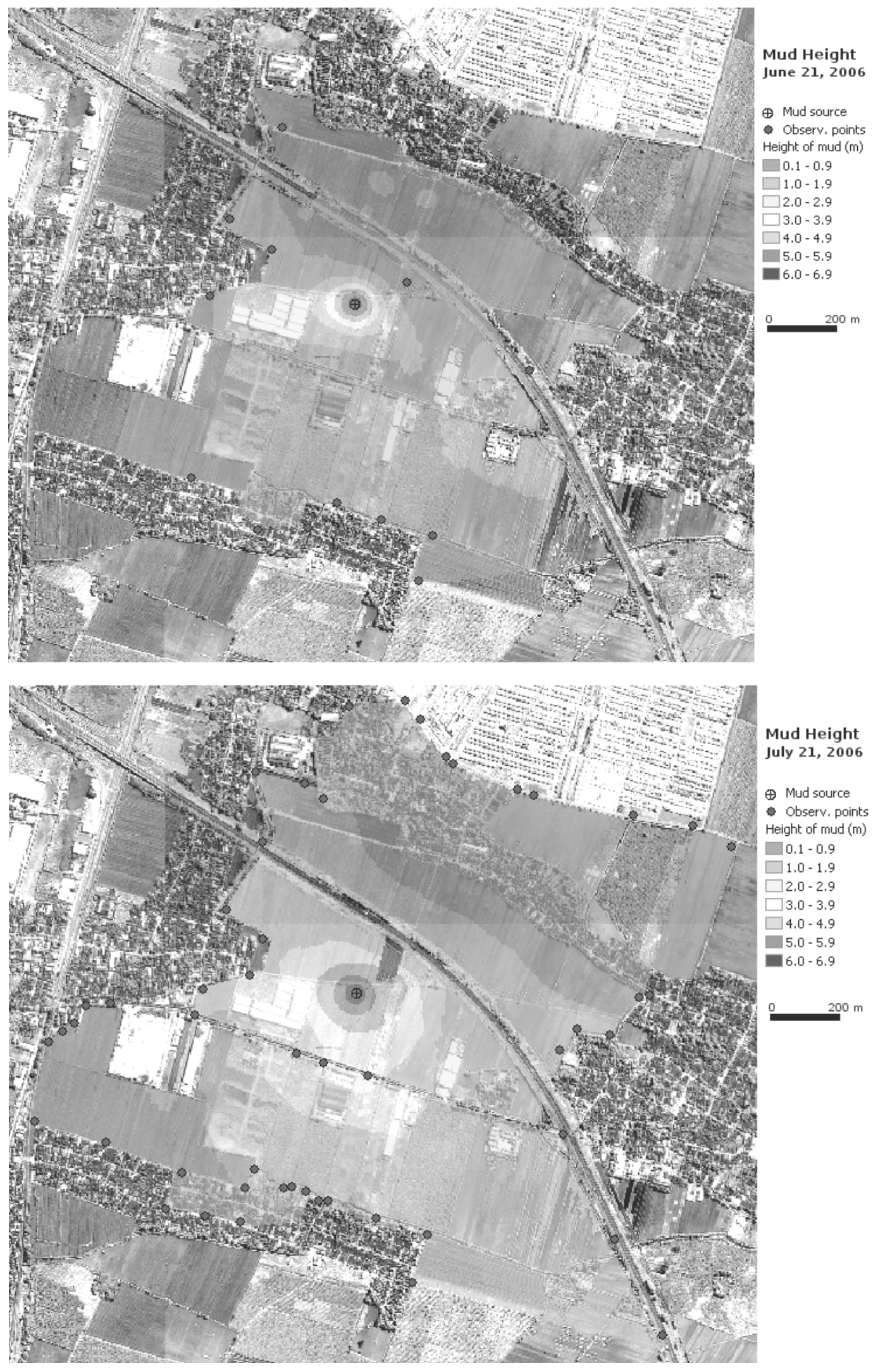

Gambar 2: Peta lokasi pengukuran dan sebaran ketinggian lumpur. 
Irregular Network (TIN) untuk mendapatkan volume danau.

Contoh lain adalah penghitungan volume sedimen Bauxite di dasar danau yang dilakukan oleh Price (2002). Tujuan dari analisa ini adalah untuk menentukan berapa lama waktu yang diperlukan untuk menambang sedimen tersebut. Data yang digunakan adalah hasil pengukuran ketebalan sedimen dasar danau. Metode Price (2002) ini yang akan digunakan untuk menghitung dimensi lumpur panas.

Perhitungan volume lumpur panas dilakukan dalam beberapa tahapan. Gambar 3 menunjukkan diagram alur pemrosesan data.

\section{HASIL DAN PEMBAHASAN}

1. Data yang dikumpulkan dari survei lapangan dengan menggunakan GPS disimpan dalam sistem koordinat geografi. Untuk dapat menghitung dimensi lumpur, data tersebut ditransform dalam sistem Universal Transverse Mercator (UTM) dalam satuan meter. Datum yang digunakan adalah World Geodetic System (WGS) 1984 zone 49.

2. Karena posisi geografis yang didapatkan dari GPS genggam memiliki error sekitar 10 meter, maka letak pengukuran tinggi lumpur dikoreksi dengan menggunakan peta rupabumi Indonesia (RBI) dan citra satelit resolusi tinggi. Peta RBI yang digunakan adalah lembar 1608-134 skala 25.000 dan citra satelit yang digunakan adalah citra Ikonos dengan resolusi 1 meter yang diambil pada tahun 2002.
3. Data ketinggian lumpur kemudian diinterpolasi untuk mendapatkan sebaran ketinggian lumpur pada wilayah yang tergenang. Beberapa titik ketinggian di pojok luapan lumpur ditambahkan untuk menghasilkan interpolasi yang lebih akurat. Interpolasi dilakukan dengan metode natural neighbor yang memberikan hasil interpolasi yang lebih realistis dengan pola sebaran lumpur. Data hasil interpolasi adalah raster dengan format grid dengan resolusi sebesar 5 meter.

4. Asumsi yang digunakan untuk perhitungan volume adalah dasar dari wilayah yang tergenang adalah datar. Hal ini dapat dibenarkan karena garis kontur pada peta RBI skala 1:15.000 menunjukkan wilayah yang datar.

5. Data format grid dengan ketinggian 0 meter dibuat sebagai data titik ketinggian dasar.

6. Analisa tiga dimensi dengan fungsi cut/ fill digunakan untuk menghitung volume berdasarkan data ketinggian lumpur dan ketinggian dasar.

Peta ketinggian lumpur pada tanggal 21 Juni dan 21 Juli 2006 terlihat pada Gambar 2. Tinggi lumpur pada pusat semburan tidak berubah begitu banyak yaitu dari 6,5 meter ke 7,0 meter. Hal ini dikarenakan pembukaan kolam penampungan di sebelah utara jalan tol sehingga lumpur tidak menumpuk dan dapat tersebar, sedang ketinggian genangan secara umum naik sekitar 1,5 meter. Hal ini menunjukkan kenaikan volume lumpur dalam jangka waktu satu bulan. 


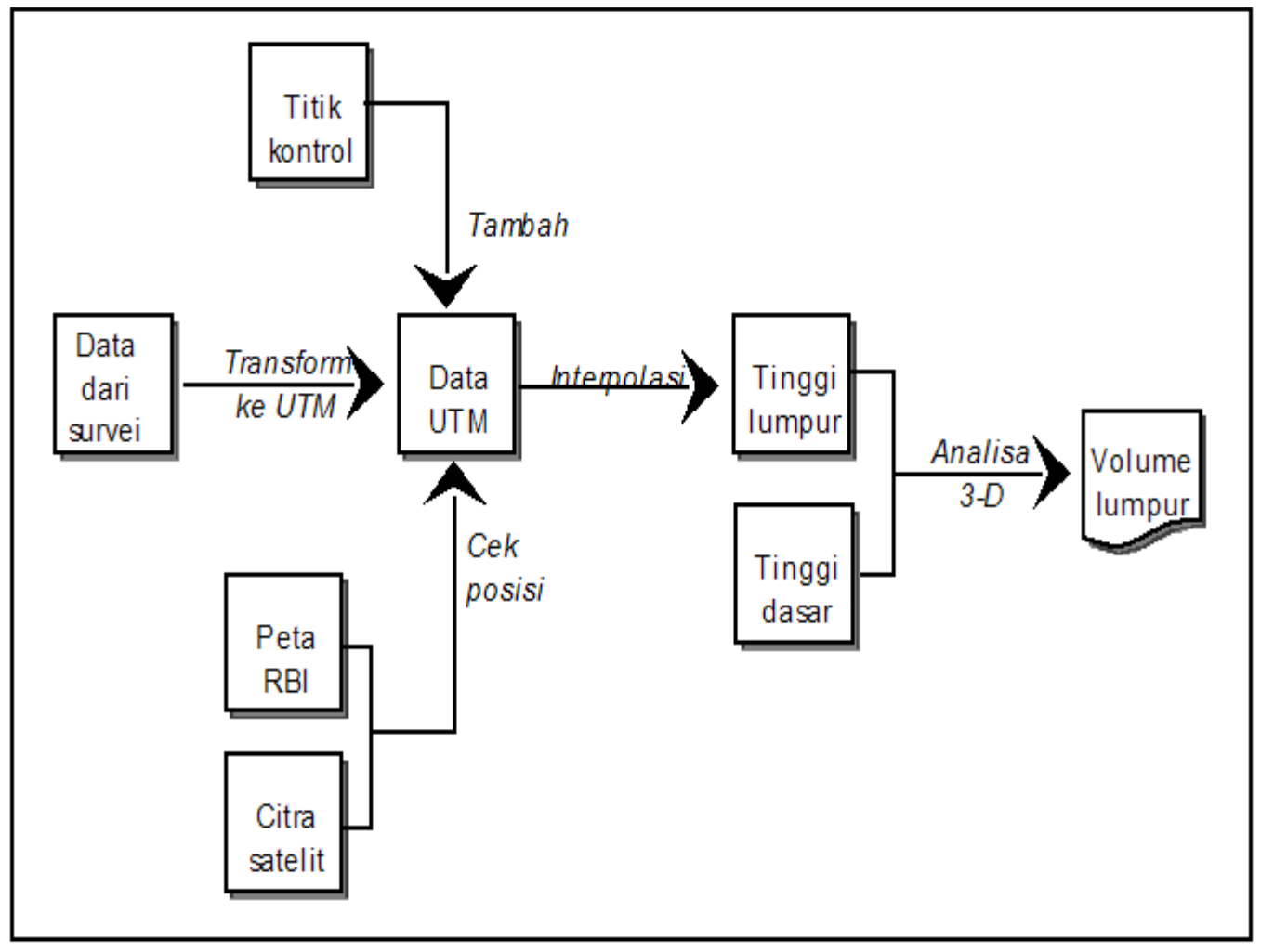

Gambar 3: Alur diagram dari analisa SIG

Tabel 1 menunjukkan perkembangan dimensi lumpur panas yang terdiri dari keliling, luas, volume dan debitnya. Luas genangan lumpur menjadi sekitar 179 hektar setelah sebelumnya sekitar 111 hektar. Dalam sebulan, volume lumpur telah bertambah lebih dari 2 kali lipat menjadi sekitar 2,5 juta $\mathrm{m}^{3}$. Semua parameter menampakkan kenaikan dalam kurun satu bulan, hanya nilai debit lumpur saja yang turun sedikit sekitar 10 persen. Belum ada penjelasan yang pasti mengapa perhitungan debit lumpur menurun.

Tabel 1: Perkembangan lumpur antara 21 Juni dan 21 Juli 2006

\begin{tabular}{|c|c|c|c|c|}
\hline $\begin{array}{c}\text { Tanggal } \\
\text { survei }\end{array}$ & $\begin{array}{c}\text { Keliling } \\
\mathbf{( m )}\end{array}$ & $\begin{array}{c}\text { Luas } \\
\mathbf{( h e k t a r})\end{array}$ & $\begin{array}{c}\text { Volume } \\
\mathbf{( \mathbf { m } ^ { 3 } )}\end{array}$ & $\begin{array}{c}\text { Debit } \\
\left.\mathbf{( \mathbf { m } ^ { 3 }} \mathbf{\text { hari }}\right)\end{array}$ \\
\hline 21 Juni 2006 & 6.523 & 110,84 & 1.117 .282 & 50.785 \\
\hline 21 Juli 2006 & 9.200 & 178,89 & 2.457 .422 & 44.671 \\
\hline Perbedaan & 2.677 & 68,05 & 1.340 .140 & -6.114 \\
\hline
\end{tabular}




\section{KESIMPULAN DAN REKOMEN-} DASI

Penelitian ini menunjukkan bahwa Sistem Informasi Geografis (SIG) telah berhasil digunakan untuk penanganan bencana alam terutama perhitungan dimensi semburan lumpur panas di Kecamatan Porong, Sidoarjo. Ketika hasil perhitungan ini disampaikan sempat terjadi keraguan karena nilai debit lumpur sebesar $50,000 \mathrm{~m}^{3}$ dirasa lebih tinggi dari yang sebelumnya diestimasi oleh beberapa ahli kebumian dengan melalui proses pengukuran. Tetapi setelah melihat akurasi metode yang digunakan dan realitas di lapangan, maka nilai debit tersebut dapat diterima. Bahkan nilai debit lumpur ini kemudian digunakan oleh media massa ketika memberitakan bencana alam ini.
Rekomendasi yang diberikan dari hasil penelitian ini adalah perlunya dilakukan pengukuran lumpur secara berkala agar diketahui kenaikan atau penurunan aktifitas semburan lumpur, sedang untuk meningkatkan akurasi perhitungan berikutnya, tingkat pergeseran tanah secara horisontal maupun vertikal (uplift dan subsidence) perlu diperhatikan. Bila pergeseran tanah dimasukkan dalam perhitungan maka asumsi bahwa dasar lumpur adalah datar harus ditinggalkan.

\section{TERIMAKASIH}

Terimakasih disampaikan kepada pihak Bakosurtanal, ITS, ITB dan Lapindo Brantas Inc. yang telah memberikan dukungan untuk pelaksanaan penelitian ini.

\section{DAFTAR PUSTAKA}

Cyranoski, D. 2007. Muddy Waters. Nature 445: 812 - 815.

Davies, R.J. 2007. Birth of a Mud Volcano: East Java, 29 May 2006. GSA Today 17 (2).

Haryadi, B. 2007. "Aplikasi Penginderaan Jauh dan SIG untuk Penetapan Tingkat Kemampuan Penggunaan Lahan (KPL) (Studi Kasus di DAS Nawagaon Maskara, Saharanpur-India)". Forum Geografi, Vol. 21, No. 1, Juli 2007. Hlm 69-77.

Joint UNEP/OCHA Environment Unit. 2006. Environmental Assessment: Hot Mud Flow in East Java, Indonesia. Technical Report June 2006.

Mazzini, A., Svensen, H., Akhmanov, G.G., Aloisi, G., Planke, S., Malthe-Sørenssen, A., and Istadi, B. 2007. Triggering and Dynamic Evolution of the LUSI Mud Volcano, Indonesia. Earth and Planetary Science Letters 261: 375-388.

Pendrod, K., Ellsworth, A. and Farrel, J. 2006. Application of GIS to Estimate the Volume of the Great Johnstown Flood. http://www2.nature.nps.gov/ParkScience/ index.cfm?ArticleID=74 (7 Desember 2006).

Price, M. 2002. Deriving Volume with ArcGIS Spatial Analyst. ArcUser. http://www.esri.com/ news/arcuser/1002/files/volumes.pdf (18 Juni 2006). 
University of Alberta. 2001. Calculating the Volume of a Lake Using ArcView 3.2. http:// www.biology.ualberta.ca/facilities/gis/uploads/instructions/AVLakeVolume.pdf (7 Desember 2006).

World Health Organization. 2006. Hot Mud Flood, Sidoarjo, East Java. Emergency Situation Report 7. 